\section{Effects of increased processing load on parallel processing of visual displays}

\author{
JANE MARANTZ CONNOR* \\ Vanderbilt University, Nashville, Tennessee 37203
}

Three experiments were performed to determine whether displays processed in parallel would be processed serially if the information requirements in the task were increased. In Experiments 1 and 2, this increase consisted of an additional nonvisually confusing input. Mean reaction time increased, but parallel processing of the displays was still observed. In Experiment 3, the difficulty of the task was increased by including displays requiring fine discriminations. For both these visually confusing displays and the highly discriminable displays processed in parallel in Experiments 1 and 2, serial processing was observed.

Numerous investigators have receritly been concerned with whether items and/or dimensions of items in a visual display are processed serially or in parallel (Egeth, Jonides, \& Wall, 1971; Egeth, 1966; Neisser, 1963; Sternberg, 1967; Donderi \& Zelnicker, 1970; Beller, 1970; Bamber, 1969). Although an appropriately modified parallel processing model can account for a positive relationship between reaction time (RT) and the number of items processed (Atkinson, Holmgren, \& Juola, 1969; Egeth, 1966), such a finding is usually interpreted as evidence of serial processing and the lack of such a relationship as evidence of parallel processing. Generally, parallel processing is observed in very simple discrimination tasks (Donderi \& Zelnicker, 1969; Donderi \& Case, $1970)$ and in judgments of physical identity (Beller, 1970, Experiment 1; Bamber, 1969). Serial processing usually occurs when items in the display must be classified on the basis of information in short-term and long-term memory (Sternberg, 1967; Beller, 1970; Neisser, 1963). Researchers concerned with the analogous questions of serial or parallel memory search have achieved some success in isolating experimental conditions which determine the mode of processing observed in a particular task (Marcel, 1970; Neisser, 1963; Graboi, 1970). The research reported here applies the same approach to the processing of visual displays. That is, given a display which is observed to be processed in parallel under some conditions, under what conditions will it be processed serially? One possible approach is suggested by the work of Connor (in press).

Employing a Stemberg paradigm, Connor varied memory or target set

*I would like to thank Dominic W. Massaro and Robert $C$. Calfee for their help in the preparation of this manuscript. This research was supported in part by a NIMH predoctoral grant to the author. interval between the presentation of the two sets. In two experiments, she found evidence for the existence of a serial encoding stage operating on the memory set. In the second experiment, the auditory and visual confusability of the memory and target sets was also varied. The results suggested that the items in the test set were serially encoded at the shorter delays (when the encoding of the memory set was not yet completed) and encoded in parallel at the longest delay. This conclusion, that a change from parallel to serial encoding occurred when part of the S's capacity was absorbed with an earlier input, was highly dependent upon parameter estimates from a complex model. There is little direct support for this hypothesis, but some indirect evidence exists in the attention literature. Treisman (1969) discusses several experiments which indicate that $S$ s have difficulty applying the same set of analyzers to competing inputs. The results of Marcel (1970) suggest that parallel memory search is limited by the extent to which the representations in memory are defined by the same dimensions. If it is assumed that the processes of forming memory and test set representations employ some of the same visual analyzers, it is possible that similar limitations might apply to display processing.

The present experiments pursued this question directly. What is the effect of an increased processing load on the parallel processing of items in a visual display? In the first two experiments, processing load was increased by having $S s$ attend to an additional visual input. In Experiment 1, this additional input was an independent memory load. In Experiment 2, a cue indicating the relevant dimension of response was presented. In Experiment 3, the processing requirements of the task size, test or visual set size, and the were increased by varying the discriminability of items in the display. The relatively simple paradigm of Donderi and Zelnicker (1970) was used, since this task requires no practice on the Ss' part to process items in parallel.

\section{EXPERIMENT 1}

An independent memory load was briefly presented prior to the exposure of the same-different display. Ss reported the items in the memory set after responding "same" or "different" to the display, It was assumed that the process of encoding the memory items, rather than their retention in memory, would require active attention and that this encoding takes time proportional to the number of items to be encoded (Sperling, 1960; Connor, in press). Thus, increasing the memory load and decreasing its presentation time (the time available to encode the items before the same-different display was presented) should have converging effects. A change from parallel to serial processing, then, would be expected to occur at a large memory load with a short delay between the presentation of the two displays.

Method

Procedure. A "ready" signal from E, informing $S$ to begin the trial by pressing a button with the thumb of his left hand, preceded each trial. A trial consisted of the following sequence of events: (1) 200 msec after the start button was depressed by $S$, a blank preexposure field went off and Field 1 of the tachistoscope was illuminated for either 50 or $500 \mathrm{msec}$; (2) the blank field was illuminated for $200 \mathrm{msec}$; and (3) the same-different display in Field 2 was illuminated for $1,500 \mathrm{msec}$.

During Sessions 1-3, Field 1 was always blank. These 3 days served as practice and were included in the experiment to observe any changes in mode of processing the display as a function of practice. On Days 4-7, Field 1 was either blank or contained a card with 1,2 , or 4 digits for a given block of 36 trials. Within a block, the memory set was illuminated for either 50 or $500 \mathrm{msec}$ in the first 18 trials and illuminated for the other duration in the second 18 trials. The order of exposure times within a block and blocks within days was counterbalanced across Ss. Each memory load set appeared with each same-different set an equal number of times. Ss were informed of the memory load and exposure duration for each subblock of trials.

The Ss were instructed to respond as rapidly as possible without making mistakes. The index finger of the right 


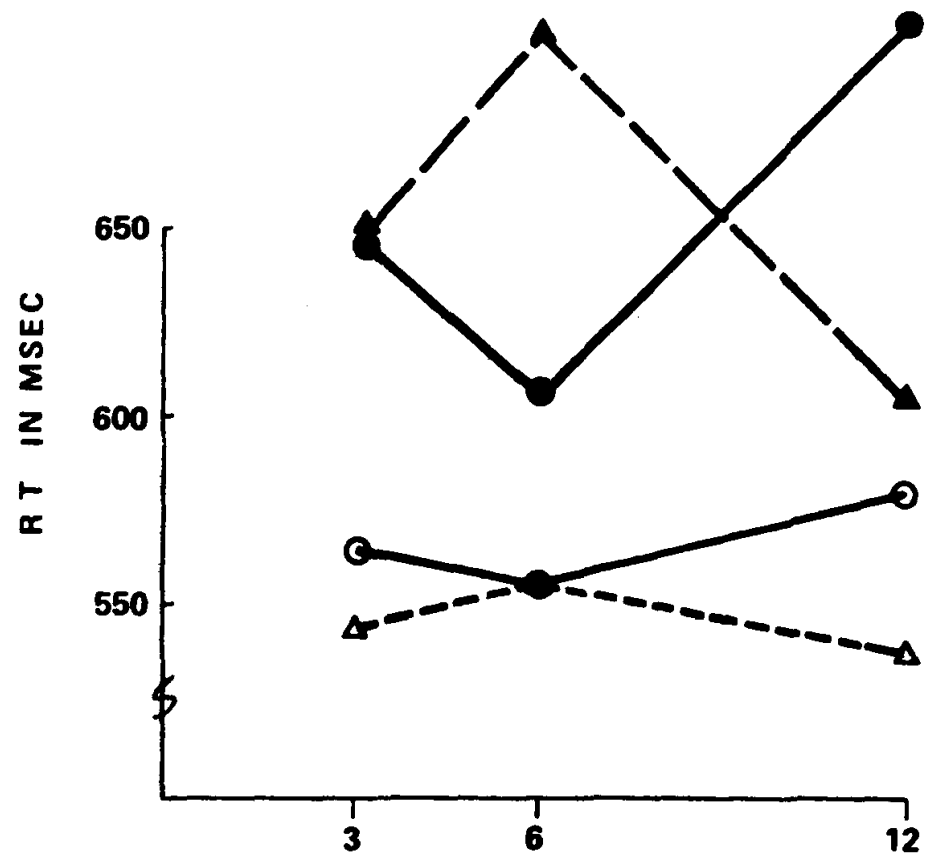

\section{NUMBER OF DISPLAY ITEMS}

Fig. 1. RT as a function of number of display items and response. Experiment 1.

hand rested on the same button and the middle finger of the right hand rested on the different button for half the Ss. The other half had the reverse assignment.

Stimuli. Displays to which Ss responded "same" or "different" were composed of black capital letters (Normatype Condensed Gothic, 24-pt). All letters of the alphabet appeared approximately equally often. A two-row array with seven positions in each row was defined and letters were assigned randomly to the positions in this array, with the restriction that for each display one of the two extreme points on the left and right sides of the card be filled. The displays subtended a visual angle of 1 deg vertically and 3 deg horizontally. Each letter subtended approximately $15 \mathrm{~min}$ of visual angle.

Eight sets of 36 display cards were constructed. Each set contained 12 cards with 3 letters, 12 cards with 6 letters, and 12 cards with 12 letters. Half of these cards were composed of all the same letter. Half contained one different letter. The "different" letter was chosen randomly from the alphabet, with certain highly visually confusable combinations eliminated (e.g., $O$ with $Q$, see Connor, 1971).
The order of cards within a set was randomized at the beginning of the experiment.

The cards containing the memory set were constructed of black digits (Normatype Futura demibold, 24-pt). The digits were centered in a row which would appear $1 \mathrm{deg}$ of visual angle above the top row of the same-different displays if the two displays were presented simultaneously. The largest set of four digits subtended 1 deg of visual angle. Six sets of 36 cards were constructed, two sets each of 1,2 , and 4 digits.

Apparatus. Stimuli were presented to Ss in a three-channel Iconix 6131 tachistoscope controlled by an Iconix 6010 frame timer, an Iconix 6131 lamp driver, and an Iconix 6083 logic system. The luminance of all three fields was adjusted to $25 \mathrm{fL}$. Reaction time (RT) was measured by an Iconix 6255 clock.

Subjects. Eight Stanford undergraduates were paid for participating in the experiment. They served for 7 days with four blocks of 36 trials per day. All Ss were right-handed.

Mean RT to the same-different

display was computed for each $\mathbf{S}$ and session at each experimental condition (correct responses only). For Days 1-3, without a memory load, RT did not differ as a function of the number of letters in the display at any level of the other experimental variables. The results show that the $S$ s were processing the displays in parallel.

On Days 4-7, mean RT did not increase with increases in display size. Nor was there any difference in mean RT for 3,6 , or 12 letters in the display at any level of memory load or exposure duration. This implies that the manipulations of memory set size and exposure duration did not change the parallel processing observed on Days 1-3. The error data also support this conclusion. The relative frequencies of errors (RFE) in the recall of memory items and incorrect responses to the display were unrelated to the number of items in the display.

A significant interaction between number of items in the display and response (same or different) was obtained (see Fig. 1). Increases in same RT were associated with decreases in different RT. Further, decreases in RT for a given response were associated with decreases in the number of errors to stimuli of that type. The symmetry of the same and different RT functions and the correlation between RT and REE support the interpretation that in this paradigm same and different responses are the result of the same search processes. Fluctuations in response bias can easily account for the different effects of number of items on same and different RT. For example, with an increase in bias to say "same," same RT would decrease but the number of false sames should increase. This occurs at $n=12$. This implies that both "same" displays and "different" displays were processed in parallel and it is justifiable to average RTs for the two types of responses.

However, Fig. 2 shows that both increasing the number of digits in the memory set and decreasing the delay between the presentation of the two displays increased RT to the same-different display. Straight lines were fitted to the data by a least-squares procedure. Variations in linear trend accounted for $78.3 \%$ of the variance in this interaction.

The finding that the effect of memory set size on RT was greatly reduced at the longer delay is taken as reflecting the existence of a serial encoding stage operating on the memory set. It is hypothesized that once encoding of the memory set is completed, further attention is not required to maintain the items in memory for the brief duration between presentation and recall. 


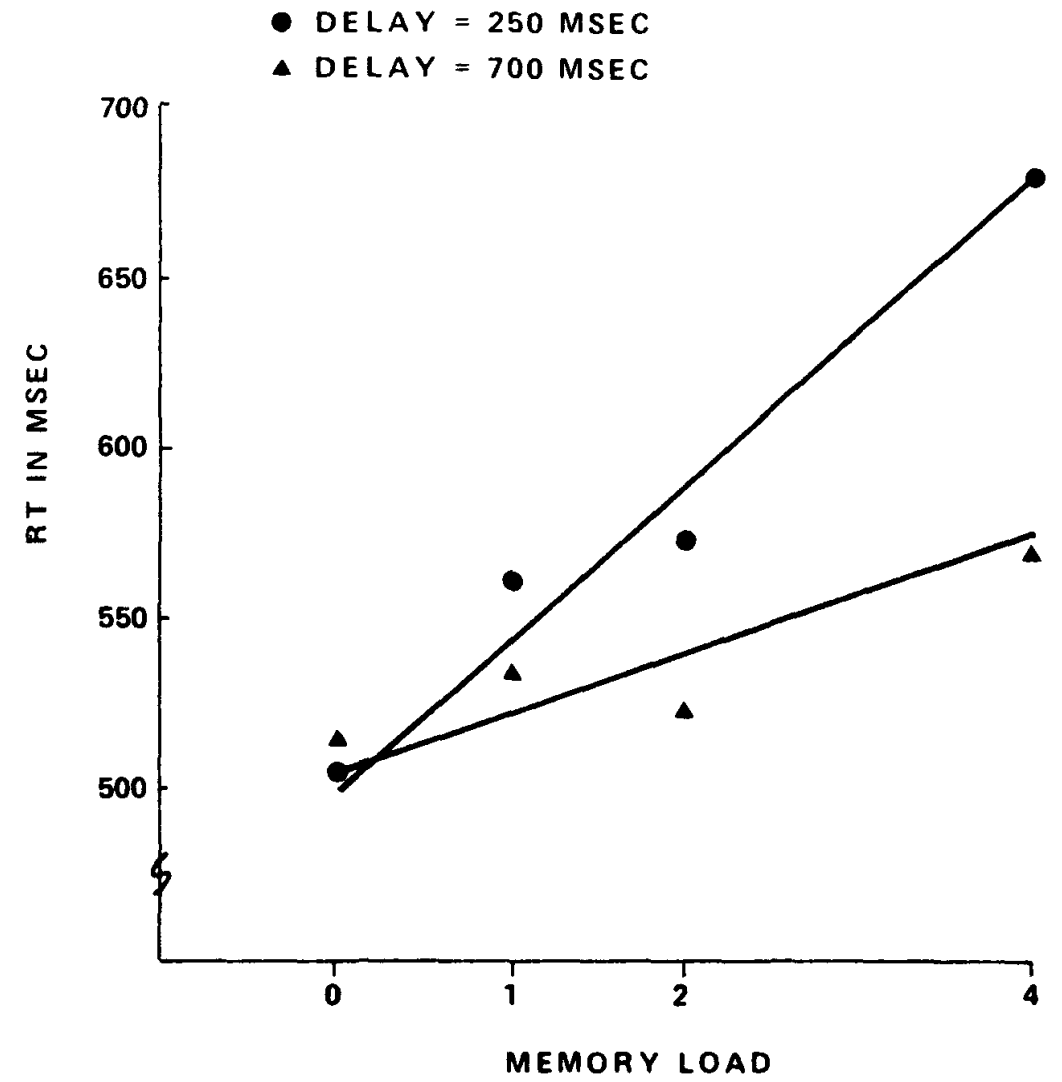

Fig. 2. RT as a function of memory load and interstimulus delay. Experiment 2.

STAGE 1

STAGE 2

STAGE 3

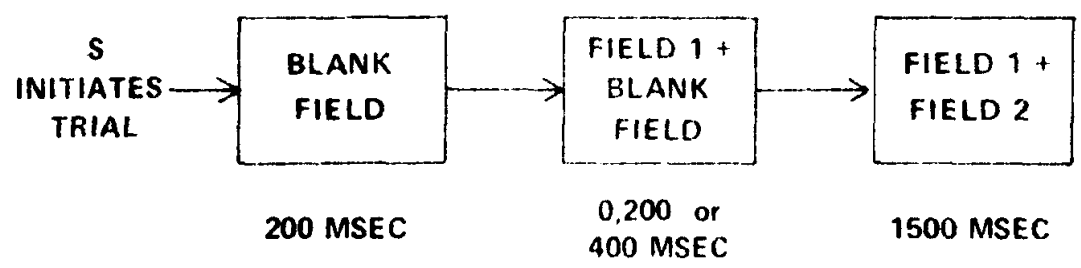

Fig. 3. Sequence of events. Experiment 2.

Table 1

Deseription of Conditions: Experiment 2

\begin{tabular}{lccc}
\hline Condition & $\begin{array}{c}\text { Card Inserted } \\
\text { in Field 1 } \\
\text { (First Card } \\
\text { Exposed) }\end{array}$ & $\begin{array}{c}\text { Card Inserted } \\
\text { in Field 2 } \\
\text { (Second Card } \\
\text { Exposed) }\end{array}$ & $\begin{array}{c}\text { Time Between } \\
\text { Onset of } \\
\text { Fields 1 \& 2 } \\
\text { (Mrec) }\end{array}$ \\
\hline C400D & Cue & Display & 400 \\
C200D & Cue & Display & 200 \\
CD & Cue & Display & 0 \\
D200C & Display & Cue & 200 \\
D400C & Display & Cue & 400 \\
Blocked Cue & Blank & Display & 0
\end{tabular}

Presumably, with a longer delay, the digits would have been completely encoded before the onset of the same-different display and no effect of memory load would have been observed. mode of processing (as opposed to the duration of processing) as a function of memory load in this experiment may relate to the independence of the two tasks. In the experiment by Connor described earlier, the correct response to the display was contingent upon the outcome of the encoding process. The memory set could not be simply stored away with minimal processing for later retrieval. The processes of encoding the digit and making the same-different judgment in the present experiment, however, were logically independent. To the extent that Ss have difficulty in attending to the sets of inputs simultaneously, an increase in the processing requirement of one input would be expected to affect the efficiency of processing the other. However, the lack of interaction of the variables affecting the processing requirements of the memory load (memory set size and delay) with the variables affecting the processing of the same-different display (response and number of items) suggests that the processing of the two sets of inputs was functionally as well as logically independent. That is, the stages of processing leading to recall of the digits were distinct from those leading to a response of same or different.

\section{EXPERIMENT 2}

In Experiment 2, the processing of a display was examined when the correct response to the display was contingent upon the completion of the processing of an additional input. A cue letter appeared at various times relative to the onset of the same-different display, indicating the relevant dimension of response for that trial. Thus, the presentation of the letter $\mathbf{C}$, for color, for example, indicated that $\mathrm{Ss}$ should respond same if, and only if, the letters in the display were the same color. It was hypothesized that with simultaneous presentation of cue and display, Ss would be processing cue and display concurrently and the two tasks would be mutually interfering. This would be indicated by a change from parallel to serial processing of the display or an increase in the latency of the same or different decision.

Method

Procedure. Each session was divided into six blocks of trials corresponding to six different conditions in the experiment. In five of the conditions, a cue card was presented on each trial indicating the relevant dimension for that trial: color, letter, or size. The tachistoscope was programmed for the sequence of events depicted in Fig. 3. The blank field remained illuminated 


\section{LETTER DISPLAY}

$\begin{array}{lll}K & K & K \\ S & K & K\end{array}$

\section{LETTER DISPLAY}

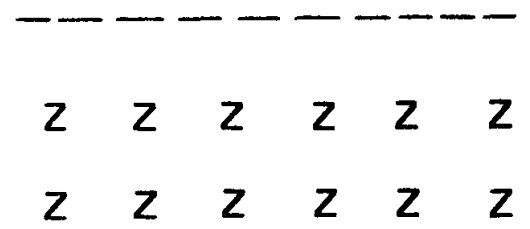

\section{LETTER DISPLAY}

Fig. 4. Typical stimuli. Experiment 2.

in Stage 2 so that the luminance of Stages 2 and 3 would be equal. In Table 1, the order and temporal sequence of the stimuli in each condition are described. The condition labels may be decoded as follows: C400D indicates that the cue was presented $400 \mathrm{msec}$ prior to the onset of the display, $C D$ refers to simultaneous presentation of cue and display, and $\mathrm{D} 400 \mathrm{C}$ indicates that the onset of the display preceded the onset of the cue by $400 \mathrm{msec}$. In all cases, the offset of the cue and the display were simultaneous and occurred 1,500 msec after the letter of the two onsets. Each day, 72 trials under each of these conditions were presented. In the sixth condition (blocked cue), Ss were informed for each subblock of 24 trials which dimension was relevant for that group of trials. Each dimension was relevant for one subblock of 24 trials each day, and the order of relevant dimensions within this condition was balanced across Ss and days. The order of conditions within a session was balanced across Ss and days. The six sets of material constructed were used equally often under each condition.

Half of the Ss had one assignment of fingers to response buttons, as in Experiment 1, and half had the other. The Ss were informed of the task requirements of the conditions and were given two practice trials each day at the beginning of each condition.

Stimuli. Six sets of 72 pairs of cards were constructed (a pair consisted of a cue card and a display card). Each set contained one each of the following factorial combinations: correct response (same or different) by number of letters in the displays $(3,6$, or 12) by relevant dimension (color, letter, or size) by status of irrelevant di mensions (s a me-s a me, same-different, different-same, or different-different). Only one different letter was present on a card; thus a card with differences on two or three dimensions contained 1 letter differing on these dimensions and 2,5 , or 11 letters homogeneous with respect to all three dimensions.

Red and blue letters were used for the display cards (Letraset Futura demibold, 18- and 24-pt) and black ones for the cue cards (Letraset Futura demibold, 24-pt). All letters of the alphabet were used for the same-different cards except for the letters, $C, L$, and $S$, which were the letters used for cueing the relevant dimension.

When there were 3 letters in the display, 1 letter was always in the center of the field and the other 2 were at the endpoints of the imaginery horizontal line $1.5 \mathrm{deg}$ of visual angle on either side of the center letter (see Fig. 4). When there were 6 letters in the display, 3 letters were positioned slightly above and 3 slightly below the positions of the letters in the 3-letter cards. When there were 12 letters in the display, the letters were in two rows of 6 letters each. The cue letters were placed so that when the cue card and display card were shown together, the bottom of the cue letter appeared 1 deg of visual angle above the top row of the display cards with 6 and 12 letters.

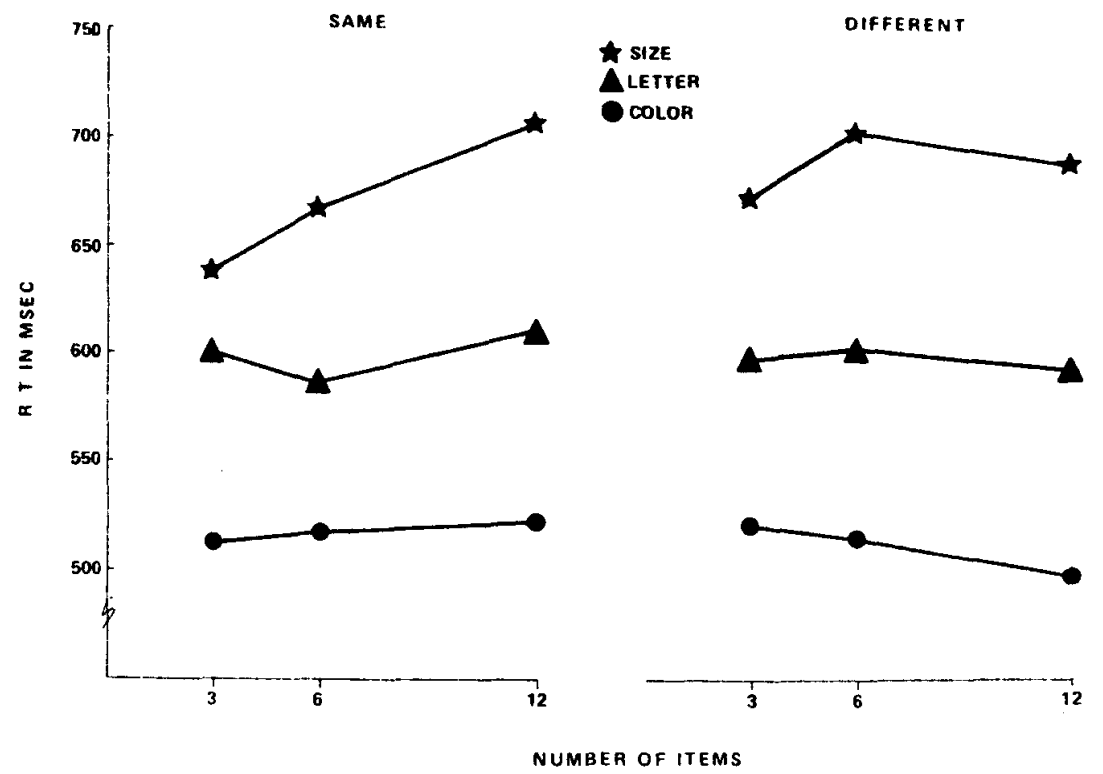

Fig. 5. RT as a function of number of items, response, and relevant dimension. Experiment 2.
Subjects. Four stanford undergraduates were paid for participating in this experiment. They served for 10 sessions.

\section{Results}

In the conditions where the onset of the cue preceded the onset of display, RT was measured from the onset of the display. In the cue after conditions, it was measured from the onset of the cue. Mean RT was computed for each $S$ for each experimental condition for Days 1-5 and $6-10$, and submitted to an analysis of variance.

Mean RT did not differ as a function of the number of items in the display when color and letter were the relevant dimensions (Fig. 5). When size was the relevant dimension, there was a significant increase in RT for same judgments with increases in $\mathrm{n}$ (lsd = $16.2 \mathrm{msec}, \mathrm{p}=.01$ ).

For different responses with size relevant, RT was significantly shorter when there were 12 items in the display than when there were 6 , a finding that neither a serial nor a parallel model can account for. The error data showed a similar pattern (Table 2), but the changes in RFE as a function of $\mathbf{n}$ were no greater when size was relevant than when color was relevant. This implies that response biases alone were not responsible for the above result. One possible explanation concerns the way in which the display cards were constructed. When there were 12 items in the display, the horizontal spaces between adjacent letters were much smaller.
Apparatus. Same as Experiment 1. 
Table 2

Experiment 2: RFE as a Function Relevant Dimension, Irrelevant Dimensions, Response, and Number of Items

\begin{tabular}{|c|c|c|c|c|c|c|c|c|c|}
\hline \multirow{2}{*}{$\begin{array}{l}\text { Number } \\
\text { of Items }\end{array}$} & \multirow{2}{*}{$\begin{array}{l}\text { Irrelevant } \\
\text { Dimension }\end{array}$} & \multicolumn{3}{|c|}{ Same } & & \multicolumn{3}{|c|}{ Different } & \\
\hline & & Color & Letter & Size & & Color & Letter & Size & \\
\hline $\mathbf{3}$ & $\begin{array}{l}\text { SS } \\
\text { SD } \\
\text { DS } \\
\text { DD }\end{array}$ & $\begin{array}{l}1.6 \\
1.2 \\
3.7 \\
5.8 \\
3.1\end{array}$ & $\begin{array}{l}0.8 \\
5.8 \\
3.3 \\
5.0 \\
\mathbf{3 . 7}\end{array}$ & $\begin{array}{l}1.2 \\
8.7 \\
4.6 \\
8.3 \\
5.7\end{array}$ & $\begin{array}{l}1.2 \\
5.2 \\
3.9 \\
6.4 \\
4.2\end{array}$ & $\begin{array}{l}3.7 \\
6.7 \\
1.7 \\
0.4 \\
3.1\end{array}$ & $\begin{array}{l}7.9 \\
1.2 \\
5.8 \\
1.7 \\
4.1\end{array}$ & $\begin{array}{r}19.6 \\
9.5 \\
5.0 \\
13.7 \\
11.9\end{array}$ & $\begin{array}{r}10.4 \\
5.8 \\
4.2 \\
5.3 \\
6.4\end{array}$ \\
\hline 6 & $\begin{array}{l}\text { SS } \\
\text { SD } \\
\text { DS } \\
\text { DD }\end{array}$ & $\begin{array}{l}0.8 \\
0.8 \\
1.2 \\
2.9 \\
1.4\end{array}$ & $\begin{array}{l}0.8 \\
4.2 \\
7.5 \\
9.2 \\
5.4\end{array}$ & $\begin{array}{r}1.7 \\
6.7 \\
5.0 \\
13.7 \\
6.8\end{array}$ & $\begin{array}{l}1.1 \\
3.9 \\
4.6 \\
8.6 \\
4.5\end{array}$ & $\begin{array}{l}2.9 \\
1.2 \\
2.5 \\
1.2 \\
1.9\end{array}$ & $\begin{array}{l}7.5 \\
2.5 \\
2.9 \\
2.1 \\
3.7\end{array}$ & $\begin{array}{r}23.3 \\
14.2 \\
8.7 \\
6.2 \\
13.1\end{array}$ & $\begin{array}{r}11.2 \\
6.0 \\
4.7 \\
3.2 \\
6.3\end{array}$ \\
\hline 12 & $\begin{array}{l}\text { SS } \\
\text { SD } \\
\text { DS } \\
\text { DD }\end{array}$ & $\begin{array}{l}0.8 \\
0.4 \\
2.1 \\
3.3 \\
1.7\end{array}$ & $\begin{array}{r}0.8 \\
5.4 \\
10.8 \\
15.0 \\
8.0\end{array}$ & $\begin{array}{r}2.1 \\
13.3 \\
\mathbf{3 . 7} \\
12.1 \\
7.8\end{array}$ & $\begin{array}{r}1.2 \\
6.4 \\
5.5 \\
10.1 \\
5.8\end{array}$ & $\begin{array}{l}3.7 \\
2.1 \\
1.2 \\
0.8 \\
1.9\end{array}$ & $\begin{array}{l}6.2 \\
0.8 \\
1.7 \\
1.7 \\
2.6\end{array}$ & $\begin{array}{r}\mathbf{1 7 . 9} \\
\mathbf{3 . 7} \\
\mathbf{8 . 7} \\
\mathbf{5 . 8} \\
\mathbf{9 . 0}\end{array}$ & $\begin{array}{l}9.3 \\
2.2 \\
3.9 \\
2.8 \\
4.5\end{array}$ \\
\hline
\end{tabular}

Note-SS = same-same, $S D=$ same-different, $D S=$ different-same, $D D=$ different-different

Since the size discrimination was a difficult one, as indicated by RT and RFE measures, it is likely that Ss had difficulty in recognizing a letter as large or small in isolation. The detection of differences in size, therefore, would have been facilitated by the closeness of adjacent letters when $n$ equalled 12 .

Changes in RT with different cues, i.e., which dimension was relevant, indicated that color was the easiest dimension, letter next, and size the hardest $(514,596$, and $675 \mathrm{msec}$, respectively). This was the expected order of difficulty and was used in the definition of the irrelevant dimensions. The irrelevant dimensions could assume one of four combinations: same-same, same-different, different-same, and different-different, where the first label refers to the more salient irrelevant dimension and the second refers to the less salient. Thus, for example, if letter were the relevant dimension on a given trial and the irrelevant dimensions were "same-different," then on this trial color was same and size was different.

RT as a function of response type and the status of the irrelevant dimensions is shown in Fig. 6. Same responses were fastest when the irrelevant dimensions were both the same and slowest when both were different. The opposite finding was obtained for different responses. Comparing same RT with different $R T$, same responses were faster when both irrelevant dimensions were the same. This pattern of results held for each cue-delay condition (Table 3 ), although not all of the comparisons were significant (lsd $=52.6 \mathrm{msec}$, $\mathrm{p}=.01$ ). In particular, same RT was affected more by the irrelevant dimensions than was different RT. The irrelevant dimensions also influenced the nature of errors. Across all experimental conditions, false-same

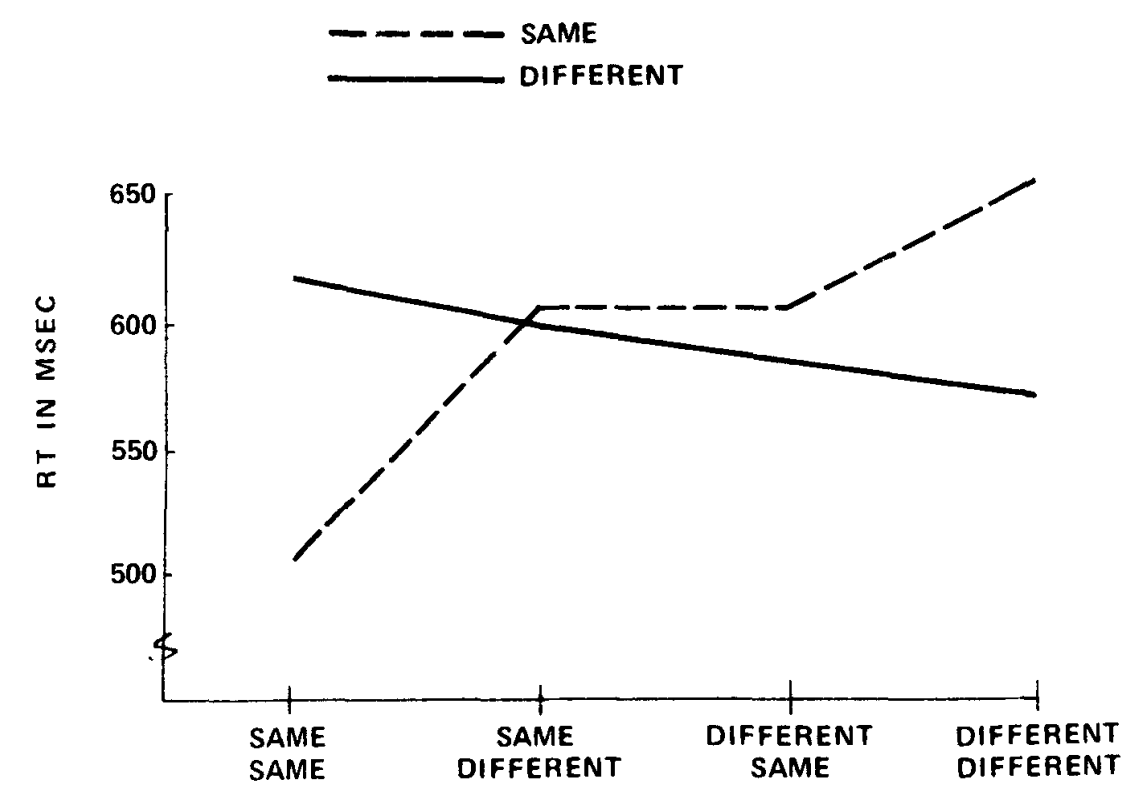

IRRELEVANT DIMENSIONS

Fig. 6. RT as a function of status of irrelevant dimensions and response. Experiment 2.

Table 3

Experiment 2: RT as a Function of Cue-Delay Condition, Response, and Irrelevant Dimensions

\begin{tabular}{|c|c|c|c|c|c|c|}
\hline \multicolumn{7}{|c|}{ Cue-Delay Conditions } \\
\hline $\begin{array}{l}\text { Irrelevant } \\
\text { Dimensions }\end{array}$ & $\begin{array}{l}\text { Blocked } \\
\text { Cue }\end{array}$ & C400D & C200D & CD & D200C & D400C \\
\hline \multicolumn{7}{|c|}{ Same Response } \\
\hline SS & 467 & 521 & 540 & 655 & 537 & 330 \\
\hline SD & 522 & 563 & 576 & 708 & 663 & 601 \\
\hline DS & 503 & 540 & 558 & 720 & 682 & 652 \\
\hline DD & 533 & 570 & 629 & 768 & 720 & 708 \\
\hline \multicolumn{7}{|c|}{ Different Response } \\
\hline sS & 517 & 541 & 592 & 735 & 676 & 646 \\
\hline SD & 510 & $\mathbf{5 2 3}$ & 565 & 707 & 664 & 632 \\
\hline DS & 504 & 517 & 574 & 688 & 650 & 622 \\
\hline DD & 481 & 512 & 554 & 681 & 640 & 605 \\
\hline
\end{tabular}


Table 4

Experiment 2: RFE as a Function of Condition, Response, and Irrelevant Dimensions

Conditions

\begin{tabular}{|c|c|c|c|c|c|c|c|}
\hline $\begin{array}{l}\text { Irrelevant } \\
\text { Dimension }\end{array}$ & $\begin{array}{c}\text { Blocked } \\
\text { Cue }\end{array}$ & C400D & C200D & $C D$ & D200C & D400C & \\
\hline $\begin{array}{l}\text { SS } \\
\text { SD } \\
\text { DS } \\
\text { DD }\end{array}$ & $\begin{array}{l}\text { Same } \\
1.4 \\
3.6 \\
5.6 \\
5.8\end{array}$ & $\begin{array}{r}\text { Stimuli ( } \\
0.5 \\
4.7 \\
6.4 \\
10.0\end{array}$ & $\begin{array}{c}\text { (False Dif } \\
2.0 \\
5.0 \\
3.0 \\
6.2\end{array}$ & $\begin{array}{r}\text { ferent } R \\
2.6 \\
8.0 \\
3.9 \\
9.5\end{array}$ & $\begin{array}{r}\text { onses) } \\
0.5 \\
5.0 \\
5.1 \\
10.6\end{array}$ & $\begin{array}{l}0.3 \\
4.8 \\
5.5 \\
9.2\end{array}$ & $\begin{array}{l}1.2 \\
5.2 \\
4.9 \\
8.5\end{array}$ \\
\hline $\begin{array}{l}\text { SS } \\
\text { SD } \\
\text { DS } \\
\text { DD }\end{array}$ & $\begin{array}{c}\text { Differ } \\
10.6 \\
4.7 \\
3.9 \\
4.4\end{array}$ & $\begin{array}{l}\text { ent Stimu } \\
5.3 \\
3.3 \\
3.1 \\
3.6\end{array}$ & $\begin{array}{c}\text { (False } \\
8.8 \\
5.5 \\
4.0 \\
3.9\end{array}$ & $\begin{array}{r}\text { Same } R \\
16.3 \\
5.1 \\
5.6 \\
3.1\end{array}$ & $\begin{array}{r}\text { onses) } \\
14.0 \\
4.7 \\
3.6 \\
3.0\end{array}$ & $\begin{array}{l}8.8 \\
3.4 \\
5.6 \\
4.4\end{array}$ & $\begin{array}{r}10.6 \\
4.5 \\
4.4 \\
3.7\end{array}$ \\
\hline
\end{tabular}

responses (errors to different stimuli) outnumbered false-different responses (error to same stimuli) when the irrelevant dimensions were both different (Table 4). The process of deciding same or different is influenced by the relative amount of sameness or difference in the display.

\section{Discussion}

The results of this experiment indicated that the detection of differences in color and form is a process operating on the display as a whole. It is not influenced by the number of items in the display. The detection of size differences was apparently the most difficult discrimination in this experiment, and some evidence for serial processing of this dimension was obtained. The size of the interval between the presentations of the cue and the display had a large effect on RT, as in Experiment 1. However, this variable did not affect the parallel processing of the color and form dimensions, nor did it affect the relationship between RT and number of stimuli when size was the relevant dimension.

Other results indicated that the status of the irrelevant dimensions systematically influenced both same and different RT. This finding is comparable to that obtained by Beller (1970, Experiment 1); increasing the number of letters or dimensions which could lead to a different response decreases different RT, while increasing the number of letters or dimensions which could lead to a same response increases different RT. The relative amount of "sameness" or "difference" in a display is an important factor influencing RT, even when a $S$ is instructed to attend to one particular dimension. The finding that this effect appeared in equal magnitude when a given dimension was relevant for a block of 24 trials suggests that the filtering mechanisms which allow Ss to ignore irrelevant dimensions do not operate well at this level of processing.

The original question asked in
Experiments 1 and 2, whether the mode of processing a visual display can be qualitatively affected (from a parallel process to a serial one) when Ss are required to divide their attention between the display and another input, remains unanswered. One reason for the conflicting answers to this question obtained in the experiments reported here and that reported by Connor (1970, Experiment 2) may concern the level of processing required in the two tasks. In the latter experiment, letters in the visual display had to be identified and compared with items in memory.

In the current experiments, Ss only had to respond to the physical sameness of the set of visually presented letters. Two dimensions of the different letters, when they occurred, were intentionally chosen so as to be physically distinctive from the other letters in the display. If only a few features had to be abstracted from each letter to make a correct response, it is possible that this low level of processing could be performed simultaneously for a number of items regardless of the difficulty of the secondary task. Evidence supporting this hypothesis relating the difficulty of the discrimination to the mode of processing was found in the data when the third dimension, size, was relevant. In this case, the most difficult discrimination, the data suggest that processing was not parallel. This implies that in a very easy discrimination task, Ss respond to the display as a whole. When a difficult discrimination is required, Ss must process the items in the display individually (i.e., serially).

\section{EXPERIMENT 3}

In Experiment 3, the relation between discrimination difficulty and mode of processing was investigated. If the parallel processing of information is a low-level preattentive function not capable of great accuracy or fine discriminations, as Neisser (1967) suggests, then increasing the difficulty of the discrimination required should change a parallel process to a serial one.

Three types of material were used: one requiring only gross discrimination for correct responding (same material as in Experiment 1) and two requiring a fine discrimination. It was predicted that displays requiring a fine discrimination would be processed serially, whereas the displays requiring only a gross discrimination would be processed in parallel. These materials were presented both as a mixed list and in groups of trials blocked by material type to observe the effects of context on the decision process.

\section{Method}

Procedure. Ss served for 12 sessions of 180 trials each. On alternate days, the trials were either blocked by type of material or materials were randomized. Two Ss began with the blocked condition first and two began with the random condition first. Three different random sequences of cards were used for each condition and these sequences were balanced across $\mathrm{Ss}$ and days. Ss were informed whether the trials were to be blocked or random each day and, in the blocked condition, were told which type of material would be presented at the beginning of each block.

Upon receiving the "ready" signal from $E$, the $S$ pressed the start button with his left thumb and the display was exposed 200 msec later. RT was measured from the onset of the display. The assignment of fingers to response buttons was balanced, as in Experiment 1.

Stimuli. Displays were composed of black capital letters on white cards. The positioning of the letters in the display and the dimensions of the letters and displays were as in Experiment 2. Six sets of 60 cards were constructed, 2 each of the three types of material. Within a set, there were 10 cards for each combination of correct response (same or different) and set size $(3,6$, or 12$)$. In the "distinctive" sets, when a different letter occurred in a display it was always very distinctive visually from the other letters (e.g., $C$ with I). In the "confusing" sets, the different letter was always visually similar to the other letters (e.g., $C$ with $O$ ). Visual similarity was defined by overlap and commonality of distinctive features (see Connor, 1971). In the "font" sets, the different letter was the same letter as the other letters but appeared in a slightly different type font. The two type fonts that were used, Normatype Universe 55 and $65,24-\mathrm{pt}$, differed only in boldness and were similar to those used in the distinctive and confusing sets (Normatype Condensed 
Gothic, 24-pt). Half of the same cards were composed of the less bold type font and half of the more bold one. The different cards were similarly constructed.

It is to be noted here that "same" cards for the confusing and the distinctive materials were, in fact, physically indistinguishable. That is, confusing and distinctive sets were defined by the type of different letters that could occur. Hence, it would be illogical for same RT in the random condition to differ between confusing and distinctive materials. This was not the case with the font material since a slightly different typeface was used for these cards.

\section{Results}

The RT data (correct responses only) was submitted to an analysis of variance. RT, as a function of material type, response, and number of items and averaged over presentation condition (blocked or random), is shown in Fig. 7. (The interaction of these factors with presentation condition was not significant.) It is seen that the rate of increase of RT with number of items was greater with the visually similar displays (confusing and font) but that the distinctive displays also showed evidence of a small increase. These results are similar to those obtained in scanning experiments where it is consistently found that visual similarity adversely affects the rate of visual search (Neisser, 1963; Connor, in press). The finding that the effect of number of items on RT was greater for same responses than for different responses is also consistent with a self-terminating scanning model and contrary to the matching models proposed by Beller (1970) and Bamber (1969).

Thee results suggest that the increased difficulty of the discrimination in this experiment required $S s$ to process the items in the display individually. The Ss were not able to respond to the display as a whole, as they had been in Experiments 1 and 2. The increase in RT for the distinctive displays as a function of set size further indicates that the mode of processing these displays (which were virtually identical to the displays used in Experiment 1) was qualitatively affected by being placed in a context of difficult discriminations. The lack of a significant interaction of presentation condition with set aize also indicates that Ss were unable to change their mode of processing on alternate days when trials were either blocked by material type or randomized.

RT, as a function of number of items and days and averaged over all other factors, is shown in Fig. 8. There was a large decrease in absolute RT and a smaller decrease in the positive relation between $R T$ and number of items with practice. At the end of the experiment, the difference in RT between $n=12$ and $n=3$ was only $50 \mathrm{msec}$, or approximately $5 \mathrm{msec}$ per letter. Practice apparently did not affect the processing of the three types of material differentially, since the higher order interactions of the days factor with material type were not significant.

The error data indicated that the results reported above were not qualified by changes in accuracy criteria (Table 5).

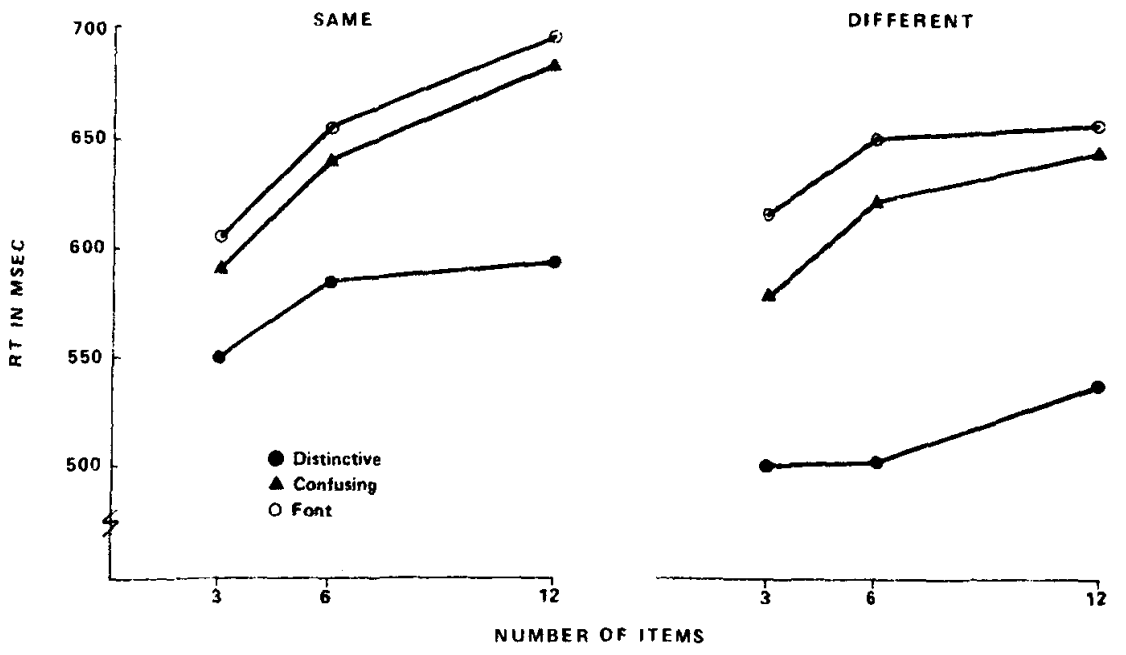

Fig. 7. RT as a function of number of items, response, and material type. Experiment 3 .

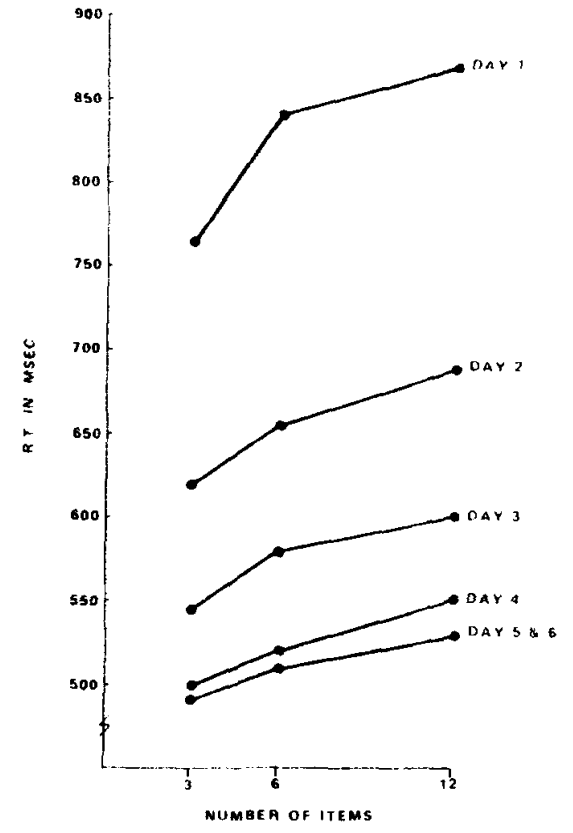

Fig. 8. RT as a function of number of items and days. Experiment 3.

\section{Discussion}

The hypothesis that the Ss must process the items in a display individually (i.e., serially) when a difficult discrimination is required was supported. The same finding has also been reported by Egeth, Jondes, and Wall (1971). The finding that an easy discrimination will also be processed serially when placed in the context of a set of difficult discriminations, even when trials are blocked by type of discrimination, implies that the Ss cannot readily change their mode of processing. The visually confusing material meant that the $S$ used a slower serial processor, and the Ss were apparently unable to switch to parallel processing for the distinctive materials but merely increased the rate of scanning slightly. It may be very difficult to achieve with a completely repeated measures design what was originally the intention of these three experiments, namely, a switch from parallel to serial processing as a function of task requirements. Although practice served to increase the rate of scanning, this increase appeared to asymptote after five sessions. That is, a change from serial to parallel processing as a function of practice, as in Neisser's work, was not obtained.

\section{GENERAL DISCUSSION}

Two main findings emerge from this set of experiments. First, increasing the information processing requirements in a task by presenting an additional input in and of itself is not sufficient to affect the parallel 
Table 5

Experiment 3: Relative Frequency of Error as a Function of Response, Number of Items, and Material (Percent)

\begin{tabular}{|c|c|c|c|c|c|c|c|c|c|c|}
\hline & & \multicolumn{3}{|c|}{ Same } & & \multicolumn{3}{|c|}{ Different } & & \\
\hline & & 3 & 6 & 12 & & 3 & 6 & 12 & & \\
\hline \multirow[t]{2}{*}{$\begin{array}{l}\text { 总 } \\
\text { 벙 } \\
0 \\
0\end{array}$} & $\begin{array}{l}\text { D } \\
\text { C } \\
\text { F }\end{array}$ & $\begin{array}{l}2.5 \\
2.9 \\
4.2\end{array}$ & $\begin{array}{l}3.7 \\
3.3 \\
5.8\end{array}$ & $\begin{array}{l}2.1 \\
2.9 \\
5.0\end{array}$ & $\begin{array}{l}2.7 \\
3.0 \\
5.0\end{array}$ & $\begin{array}{l}2.1 \\
0.8 \\
5.0\end{array}$ & $\begin{array}{l}2.5 \\
2.9 \\
2.9\end{array}$ & $\begin{array}{l}2.1 \\
2.9 \\
5.8\end{array}$ & $\begin{array}{l}2.2 \\
2.2 \\
4.6\end{array}$ & $\begin{array}{l}2.5 \\
2.6 \\
4.8\end{array}$ \\
\hline & & 3.2 & 4.3 & 3.3 & 3.6 & 2.6 & 2.8 & 3.6 & 3.0 & $\mathbf{3 . 3}$ \\
\hline \multirow[t]{3}{*}{ E్ } & $\begin{array}{l}\mathbf{D} \\
\mathbf{C} \\
\mathbf{F}\end{array}$ & $\begin{array}{l}4.2 \\
3.3 \\
2.1\end{array}$ & $\begin{array}{l}5.4 \\
2.5 \\
5.8\end{array}$ & $\begin{array}{l}1.7 \\
2.9 \\
5.4\end{array}$ & $\begin{array}{l}3.7 \\
2.9 \\
4.4\end{array}$ & $\begin{array}{r}5.8 \\
5.4 \\
13.3\end{array}$ & $\begin{array}{r}13.3 \\
8.3 \\
7.5\end{array}$ & $\begin{array}{r}9.2 \\
7.5 \\
10.6\end{array}$ & $\begin{array}{r}9.4 \\
7.1 \\
13.5\end{array}$ & $\begin{array}{l}6.5 \\
5.0 \\
9.0\end{array}$ \\
\hline & & 3.2 & 4.6 & 3.3 & 3.7 & 8.2 & 9.7 & 12.1 & 10.0 & 6.9 \\
\hline & & 3.2 & 4.4 & 3.3 & 3.6 & 5.4 & 6.2 & 7.8 & 6.5 & 5.1 \\
\hline
\end{tabular}

$D=$ Distinctive

C $=$ Confusing

$F=$ Font

processing of certain visual displays (Experiments 1 and 2). RT is increased by the additional load, either by a delay in the starting time of the display processing or by a change in the distribution of processing capacity, but the essential characteristics of the process remain unchanged. It may be that in these two experiments, the stimuli were discriminable enough for differences to be detected within the time needed to scan the display. If, however, processing requirements are increased by appropriate changes in the discriminability of the items in the basic display, serial processing may be observed (Experiments 2 and 3 ). This suggests an explanation of the contradictory findings in the two experiments by Connor described earlier. Evidence of a serial test set encoding stage, as indicated by an increase in RT as a function of test set size above that accounted for by the number of comparisons to be made, was found only in Connor's second experiment. In that experiment, the auditory and visual confusability of the test and target sets was manipulated. It appears that both the mutual confusability of the two sets of items and the short interval between the presentation of the target and test sets are necessary factors to obtain serial encoding of the test set. This conclusion is also consistent with results in the attention literature (Treisman, 1969; Marcel, 1970), suggesting that the limits of attending to several inputs simultaneously are primarily determined by the need to apply the same set of analyzers to several inputs.

The second finding concerns the effect of context on serial and parallel processing. The same displays that were processed in parallel in Experiment 1 were processed serially in Experiment 3, where they were presented in conjunction with less discriminable displays that required serial processing. To the extent that serial or parallel processing reflect different strategies that Ss may employ, placing a simple task in the context of a more difficult task may mask qualitatively different modes of processing in the two tasks. Another such example is seen in a comparison of the results of Bamber (1969) with Beller (1970, Experiment 2). Beller's physical match cards were identical to Bamber's "same" cards. Whereas Beller found that each additional pair of physically identical letters added $60 \mathrm{msec}$ to $R T$, the relation between RT and number of letters found by Bamber was sufficiently small to lead him to postulate the existence of a rapid nonserial identity reporter. With two possible qualifications, it appears that experiments seeking to obtain both serial and parallel processing within the same experiment as a function of task requirements are probably best designed as between-Ss experiments. The first qualification derives from the results of Experiment 2, where the color and letter dimensions were processed in parallel and evidence of serial processing of the size dimension was obtained. To the extent that analyzers for the different dimensions may function independently, this restriction may not apply. The second qualification arises from the work of Egeth, Jonides, and Wall (1971), who obtained evidence of parallel and serial processing of visually distinctive and visually similar display items, respectively, by the same Ss. Two major differences exist between Experiment 3 reported here and that described by Egeth et al, which may account for this discrepancy. Egeth et al used only 1 letter pair in each of the two discriminability conditions. The current experiment used 26 letter pairs in each. Half of Egeth et al's Ss were "same" detectors; half were "difference" detectors. Thus, each S responded to only one type of display. In the present experiments, all Ss gave both types of responses. It is not clear at this time exactly how these methodological variations determine context effects.

REFER ENCES

ATKINSON, R. C., HOLMGREN, J. E., \& JUOLA, J. F. Processing time as influenced by the number of elements in a visual display. Perception \& Psychophysics, 1969, 6, 321-326.

BAMBER, D. Reaction times and error rates for "same"-"different" judgments of multidimensional stimuli. Perception \& Psychophysics, 1969, 6, 169-174.

BELLER, $H$. K. Parallel and serial stages in matching. Journal of Experimental Psychology, 1970, 84, 213-219.

CONNOR, J. Factors affecting parallel processing of visual displays. Dissertation A bstracts International, 1971, 32B 3661 B. No. 71-24, 2449.

CONNOR, J. Encoding and comparison processes in memory and visual search. Journal of Experimental Psychology, in press.

DONDERI, D., \& CASE, B. Parallel visual processing: Constant same-different decision latency with two to fourteen shapes. Perception \& Psychophysics, $1970,8,373-375$.

DONDERI, D. C., \& ZELNICKER, D. Parallel processing in visual same-different decisions. Perception \& Psychophysics. $1969,5,197-200$.

EGETH, H. E. Parallel versus serial processes in multidimensional stimulus discrimination. Perception \& Psychophysics, 1966. 1, 245-251.

EGETH, H., JONIDES, J., \& WALL, S. Can the elements of a visual display be processed in parallel? Paper presented at the meeting of the Psychonomic Society, St. Louis, 1971.

GRABOI, D. Searching for targets: The effects of specific practice. Perception \& Psychophysics, 1971, 10, 200-204.

MARCEL, A. J. Some constraints on sequential and parallel processing and the limits of attention. Acta Psychologica. $1970,33,77-92$.

NEISSER, U. Decision-time without reaction-time: Experiments in visual scanning. American Journal of Psychology, 1963, 76, 367-385.

SPERLING, G. The information available in brief visual presentations. Psychological Monographs, 1960, 74(11, Whole No. 498).

STERNBERG, S. Scanning a persisting visual image versus a memorized list. Peper presented at meeting of the Eastern Psychological Association, Boston, April 1967.

TREISMAN, A. Strategies and models of selective attention. Psychological Review, $1969,76,282-299$.

(Received for publication January 3, 1972.) 